Adriel Henrique de Oliveira Sirvente

Thiago Ramos Vicente

\title{
IMPORTÂNCIA DA ANÁLISE DE CUSTOS E OS BENEFÍCIOS DE SUA APLICAÇÃO ÀS EMPRESAS
}

\author{
Trabalho de conclusão de curso \\ apresentado ao curso de Ciências Contábeis \\ das Faculdades Integradas de Fernandópolis, \\ como exigência parcial para obtenção do \\ título de bacharel em Ciências Contábeis sob \\ a orientação da professora Me. Elaine Doro \\ Mardegan Costa.
}




\title{
IMPORTÂNCIA DA ANÁLISE DE CUSTOS E OS BENEFÍCIOS DE SUA APLICAÇÃO ÀS EMPRESAS
}

\author{
Adriel Henrique de Oliveira Sirvente \\ Thiago Ramos Vicente \\ Orientadora: Prof ${ }^{\mathrm{a}}$. Me. Elaine Doro Mardegan Costa
}

\begin{abstract}
RESUMO
Desde a antiguidade o homem necessita controlar seus custos, cada qual com seus devidos fins. Com isso, surge o registro e o controle de custos que após ser aprimorado originou a análise de custos contábeis, que pode ser definida como processamento de dados do estudo das contas de custeio envolvidas no processo. Com o trabalho objetivou-se apresentar a importância da análise de custos e os benefícios de sua aplicação às empresas. Por meio da pesquisa descritiva bibliográfica e uso da análise comparativa realizou-se abordagem teórica, sendo necessário a utilização de livros e artigos científicos para apresentar os métodos de custeio por absorção e variável. Os resultados apontam os fundamentos e conceitos da análise de custos, sendo importante destacar que o estudo permite ao usuário da contabilidade, analisar seus custos a fim de alocá-los aos seus respectivos produtos. Com tais informações, o gestor terá indicadores precisos e confiáveis para mensurar o valor investido, identificar e conhecer os tipos de custos e métodos, que lhe permitirá traçar planos de ação com mais segurança, além de amparar os resultados de sua análise para tomar decisões e confrontar resultados. Conclui-se que a aplicação dos métodos de análise de custos, se fazem tão útil para o uso gerencial, quanto para atendimento às exigências legais da empresa, além de permitir a elaboração de relatórios gerenciais precisos que devolvem resultados pertinentes e relevantes. Logo, são muitos os benefícios de sua utilização para a gestão empresarial.
\end{abstract}

Palavras chaves: Análise de custos. Contabilidade de custos. Gestão. Empresas.

\begin{abstract}
Since antiquity man needs to control his costs, each one with its own goals. With that, the register and control of costs have emerged and after being upgraded, it started the costs analysis that can be defined as the study of the cost involved in the process. This work aims to show the importance of costs analysis and its advantages of application in the company. Through of the descriptive bibliographic research and the use of comparative analysis. A theoretical approach was performed, and it was necessary the use of books and scientific articles to show the absorption costing method and variable costing method. The results indicate the foundations and concepts of cost analysis and it is important to emphasize that the study allows the accountability user, to analyze its cost for allocation of the products in question. With this information, the manager will have accurate and trustworthy stat to measure the invested value, to identify and know the types of cost and methodology, that will allow the manager draw safer plans of action, besides helping to
\end{abstract}


get decisions and confront the results. Therefore, the conclusion is that the applications of analysis of cost methods are useful to management as much as to attend the fiscal company's demands, besides permitting an elaboration of precise manager's reports that give back pertinent and relevant results. So, there are a lot of benefits of its use in company administration.

Key words: Costs analysis. Cost accounting. Manager. Company.

\section{INTRODUÇÃO}

O homem sempre buscou a capacidade de controlar suas posses, tal comportamento é notado desde a antiguidade, como por exemplo, na contagem de rebanhos que foi importante para o controle numérico e refletiu na tomada de decisões. Junto com a mudança de cenário, mudou-se também as práticas e o homem passou a sentir necessidade de analisar e controlar seu patrimônio e informações econômico/financeiras. Com isso, surge o registro e o controle de custos que após ser aprimorado originou a análise de custos contábeis.

Desta forma o estudo ao evidenciar o método aplicado permite ao usuário da contabilidade, analisar seus custos a fim de alocá-los aos seus respectivos produtos e processos produtivos. Ao se utilizar de tais informações, o gestor terá indicadores precisos e confiáveis no que diz respeito a mensuração do valor investido, visando o planejamento orçamentário, definição de metas e objetivos, além de obtenção de vantagens no mercado em que está inserido.

É evidente que cada empresa possui tipos específicos de custo, e necessita que os mesmos sejam alocados, de tal forma, que retratem a real situação do processo. Além disso, existem determinados custos que podem ser diretamente atribuídos aos produtos e processos, enquanto outros necessitam de métodos especiais de rateio para definir um valor.

Com o esclarecimento do estudo, identificação e conhecimento dos custos e métodos, o gestor terá dados mais precisos que lhe permitirá traçar planos de ação com mais segurança, além de amparar os resultados de sua análise para tomar decisões e confrontar resultados.

Com o trabalho objetivou-se apresentar a importância da análise de custos e os benefícios de sua aplicação às empresas com o intuito de introduzir o gestor na prática contábil, e nos conceitos da análise de custos, que por sua vez se faz determinante na tomada de decisões, resultado de sua característica de processar relatórios fiéis aos custos envolvidos no processo produtivo. 
Para isso, este trabalho aborda dois principais métodos de custeio, com o objetivo específico de apresentar e sustentar a importância da análise de custos e os benefícios de sua aplicação ás empresas.

Trata-se de uma pesquisa descritiva bibliográfica juntamente com o uso da análise comparativa de enfoque na análise de custos e seus diferentes métodos com propósitos variados que em determinadas situações se fazem mais úteis. Sendo a coleta de dados realizada em livros e artigos científicos que abordam o referido tema, sejam impressos ou disponíveis em banco de dados eletrônicos.

\section{REVISÃO DA LITERATURA}

\subsection{Análise de Custos e seus fundamentos contábeis}

Para iniciar a apropriação dos custos, é necessário ao gestor fazer a distinção dos gastos em custos e despesas. Na teoria, essa classificação é algo simples, pois, de acordo com a NPC 2 (Norma de Procedimento de Contabilidade) do IBRACON (Instituto dos Auditores Independentes do Brasil), custo é a soma dos gastos que resultam na elaboração, transformação ou aquisição dos produtos a serem vendidos, ou na realização dos serviços oferecidos pela empresa. Enquanto despesa é o valor aplicado à manutenção da atividade da empresa, seja em bens ou serviços, e aos esforços para a obtenção de receitas através da venda dos produtos (ZANLUCA, 2015).

Pode-se definir como todo valor sacrificado para a confecção do produto ou realização do serviço. Estes gastos são utilizados seja de forma direta: no consumo de matéria prima, aquisição de bens que serão transformados ou agregados ao produto final e salários de funcionários que atuam diretamente na produção; ou seja no consumo de forma indireta: como o aluguel do galpão, energia para alimentar as máquinas, água, lubrificantes, combustível e demais produtos utilizados no processo fabril.

Depois que os gastos forem devidamente classificados e forem identificados os custos da produção, o gestor de custos deverá, então, decidir-se pelo método de custeio que julgar mais eficiente e efetivo. Para isto, deverá levar em conta as características da empresa e os processos para a realização do produto ou serviço final.

Se o método for escolhido e implantado de maneira correta, irá fornecer relatórios e informações essenciais para a tomada de decisão e para conquistar os objetivos propostos pela empresa. 
A primeira pergunta para se chegar à conclusão é: Para que se quer o sistema? É para controle, para fornecimento rápido de informações, para fins de decisões rotineiras e intempestivas, para decisões que não demandam tanta rapidez de dados ou ainda para simples avaliações de estoques a ajudar a contabilidade financeira em sua tarefa de apuração de estoques e resultados? (MARTINS, 2010, p. 360).

\subsection{Utilização da Análise de custo, suas importâncias e benefícios}

Análise de custo é uma ferramenta crucial para o gestor na formação do preço de venda, pois consiste em identificar cada ação do processo produtivo para transformar as etapas em valores. Dessa forma, entrega ao usuário de maneira gráfica a relação dos custos e os sacrifícios que foram necessários para a produção de um determinado produto ou serviço, concedendo ao gestor dados qualitativos e quantitativos mais próximos da realidade do que foi gasto no processo. Com esta informação, o gestor conseguirá atribuir valor para cada unidade, pois aplicado um percentual de lucro desejado, pode-se variar o preço dentro desta perspectiva de margem de viabilidade para evitar o prejuízo.

Caso o empresário formule um preço de venda para competir no mercado e atrair o consumidor, sem que tenha a informação precisa dos seus custos, ou o estudo dos materiais e mão de obra consumidos no processo, pode acarretar um resultado incapaz de suprir os gastos mínimos de produção, em função de um preço equivocado.

Análise de custo, aplicada ao estudo da viabilidade de uma nova atividade se faz muito importante, pois pode influenciar a direção dos seus investimentos. Desta forma, planejar a introdução de um novo produto no catálogo da empresa precisa-se entender até qual ponto é viável a sujeição à sua produção. Assim, o estudo da viabilidade "busca identificar quais são os benefícios esperados em dado investimento para colocá-los em comparação com os investimentos e custos associados ao mesmo, a fim de verificar a sua viabilidade de implementação" (HORNBURG; WEISE; ZAGO, 2009, p.2).

Por esse motivo, a utilização da análise de custo torna-se importante, já que serve para mapear o processo de produção e destacar as atividades necessárias para produzir tal produto, como também mensurar o tempo e dinheiro sacrificado no procedimento.

Assim, o gestor se baseia nessas informações para confrontar se o retorno estimado suprirá o esforço empenhado, ou se esta opção se faz inviável, o mesmo poderá buscar outras opções que sejam mais favoráveis e rentáveis. 
Em algumas situações a coleta da matéria prima ou a entrega do produto podem ser variáveis determinantes no estudo da viabilidade, pois a logística interfere diretamente no tempo e custo que são atrelados ao processo produtivo. Isso se dá ao fato que rotas mal planejadas ocasionam o desperdício de tempo inviabilizando a produção.

Um dos principais desafios da logística moderna é conseguir gerenciar a relação entre custo e nível de serviço (trade-off). O maior obstáculo é que cada vez mais os clientes estão exigindo melhores níveis de serviço, mas ao mesmo tempo, não estão dispostos a pagar mais por isso. O preço está passando a ser um qualificador, e o nível de serviço um diferenciador perante o mercado. Assim, a logística ganha a responsabilidade de agregar valor ao produto através do serviço por ela oferecido. (LIMA, 1998, p.1).

No que se refere ao retorno financeiro de determinados produtos pode-se observar que será maior se o processo for otimizado com a redução de custos. Entretanto, poderá identificar as deficiências e desperdícios existentes na fabricação do produto ou serviço, com a realização de estudo detalhado dos processos envolvidos.

$\mathrm{O}$ estudo mencionado permite mapear e destacar as atividades imprescindíveis e as que podem ser melhoradas, ou até mesmo excluídas, sem que afete negativamente o produto final.

Com esta ferramenta o gestor poderá identificar falhas que enfraquecem a eficiência do processo e terá, em mãos, informações necessárias para reformular os procedimentos para evitar gastos desnecessários, consumos exagerados, tempo vago entre as etapas e, desgaste dos equipamentos e funcionários.

Como resultado, a reorganização poderá fornecer melhores resultados, já que será possível obter recursos, com o aproveitamento e eficiência no processo, aumento da produção com o controle de tempo gasto e, assim, eliminar processos repetitivos.

\subsection{Métodos de Custeio e seus procedimentos}

São etapas realizadas de maneira sistêmica que qualifica e quantifica os custos utilizados e consumidos no processo, sendo ordenado pelas atividades empenhadas na fabricação do produto, com a finalidade de obter informações exatas que serão determinantes para atribuição dos custos ao produto de maneira fiel, sem que haja variações que podem interferir significativamente no valor real sacrificado na produção. Assim, será apresentado dois principais métodos de custeio, pois apesar de parecer simples e objetivo não podemos usar de um único método de custeio para incumbir sua análise a todo tipo de produto. Isso se 
deve ao fato de que cada produto tem sua particularidade que faz com que determinados métodos sejam incapazes de coletar dados realísticos que apresentem maior veracidade.

A importância dos métodos de custeio se dá devido ao fato da sua utilidade.

Esses métodos são utilizados para, entre muitas outras informações, determinar o valor dos objetos de custeio; reduzir custos, melhorar os processos; eliminar desperdícios; decidir entre produzir ou terceirizar; e eliminar, criar e aumentar, ou diminuir, a linha de produção de certos produtos. (ABBAS; GONÇALVES; LEONCINE, 2012, p.146).

O método de Custeio por absorção é, entre os métodos, o mais conhecido. Este modelo "consiste na apropriação de todos os custos de produção aos bens elaborados, e só os de produção; todos os gastos relativos ao esforço da produção são distribuídos para todos os produtos ou serviços realizados" (MARTINS, 2010, p.37).

Este método de custeio trata-se de uma metodologia que nasceu com a própria contabilidade de custo, derivada da aplicação dos princípios da contabilidade, e pela sua eficiência foi aderida como universal para fins de prestação de contas na avaliação dos estoques (MARTINS, 2010).

A singularidade do método está na alocação dos custos indiretos aos produtos finais, por meio do rateio dos mesmos. Já que aproxima a valorização dos produtos ou serviços ao custo real de sua realização. No entanto, oferece tentativas estimada e, algumas vezes, arbitrária na agregação de valor.

Apesar de suas limitações, a sua utilização em auditoria externa tornou-se imprescindível, resultado da incorporação de todos os custos sacrificados na produção, ou quanto aos serviços, de todos os gastos necessários para a sua realização.

A utilização do Custeio por absorção como processo padrão vai além de uma simples escolha. Por atender aos princípios da Contabilidade, este é o método mais indicado para atender as exigências da fiscalização tributária. As razões que o tornam aceitável ao físco e a Legislação do Imposto de Renda estão ligadas a diversos fatores, "entre os quais a tradição na sua utilização; a escassez de estudo sobre outros métodos com fins fiscais; e o entendimento divergente de" (BORGET; SCHULTZ; SILVA, 2008).

É importante ressaltar que a legislação vigente, recomenda apenas algumas adaptações quanto à depreciação e a alguns gastos que deverão ser lançados para compensação no resultado do exercício ao invés de serem atribuídos ao estoque.

No que se refere a sua utilização como ferramenta da contabilidade gerencial o custeio por absorção ainda apresenta muita contestação, pois deixa a desejar como ferramenta de gestão quanto a forma de atribuição dos custos indiretos. 
As divergências de pensamentos não se limitam a este ponto de vista, já que alguns autores defendem o custeio por absorção até como ferramenta para tomada de decisão. Outros preferem sistemas simples para a apuração dos custos, não deixando de utilizar ferramentas de controle de qualidade. Segundo Martins (2003, p. 357), 'o sucesso de um sistema de informações depende do pessoal que o alimenta e o faz funcionar'. O autor diz que os relatórios não podem ser, em hipótese alguma, de qualidade melhor que a qualidade dos dados recebidos no início do processamento. (SEVERIANO FILHO; MELO, 2006, p. 3).

Severiano Filho e Melo (2006), reafirmam a importância de alimentar o sistema de custeio com informações verídicas e oportunas, para que os dados colaborem com o processo, ao produzir relatórios mais precisos e pertinentes. Este pensamento ratifica a importância da capacitação dos gestores e dos responsáveis pela alimentação de qualquer sistema que a empresa decida por optar. Ainda sobre isso afirmam:

Este fato força uma reflexão à cerca de que, independente da técnica estabelecida, deve-se ter extremo cuidado com as informações. Os dados iniciais quase sempre dependem de pessoas e, se estas falharem ou não colaborarem, todo o sistema acabará por falir. (SEVERIANO FILHO; MELO, 2009, p. 3).

O segundo método a ser abordado neste trabalho, refere-se ao Custeio Direto ou Variável. Este sistema surgiu em meados do século 30, quando as empresas começavam a crescer em larga escala e enfrentavam dificuldade de apropriação dos diversos gastos que passavam a consumir. Desta forma o Custeio por Absorção, trata-se de uma metodologia cada vez mais dispendiosa e imprecisa (CLEMENTE; SOUZA, 2004 apud SEVERIANO FILHO; MELO, 2009).

O Custeio Direto atribui ao valor dos estoques apenas os custos diretos e/ou variáveis. "Dessa forma, todos os custos fixos - ou indiretos - são tratados como despesas e, não, são alocados aos produtos" (BORGET; SCHULTZ; SILVA, 2008, p.5).

A utilização deste método ocasiona características que devem ser levadas em conta pelos gestores do processo. A subavaliação dos estoques que deixam de agregar todos os gastos necessários à sua produção, a superavaliação das despesas operacionais que absorvem essa diferença totalizadora independente da venda ou não do produto, e consequentemente a redução dos lucros. Estas razões confrontam os princípios contábeis e as normas do fisco, e são contraindicados pelos profissionais para a prestação de contas e procedimentos de Auditoria.

O grande destaque atribuído à adoção do Custeio Variável, em empresas industriais de transformação, deve-se ao fato de estas 
empresas já sentirem a necessidade maior de otimizar o seu processo decisório, no momento em que experimentam a gestão descentralizada de suas atividades, elaborando sistemas produtivos capazes de sustentar e evidenciar as operações em si, através de registros contábeis mais confiáveis, evitando sobremaneira a obscuridade ocasionada pela departamentalização da produção utilizada em grande escala. (TEIXEIRA, 1993 apud MELO; SEVERIANO FILHO, 2009, p.18).

\section{CONCLUSÃO}

A aplicação dos métodos de análise de custos, é tão recomendada para o uso gerencial, quanto para atendimento às exigências legais da empresa, frente ao fisco. Tendo em vista que a alocação, ao produto ou serviço, apenas dos custos diretamente consumidos, sem que haja uma avaliação específica pode resultar em desequilíbrio ou disparidade nos resultados. Dessa forma a elaboração de relatórios gerenciais e a aplicação de índices de rentabilidade e retorno, devolvem resultados pertinentes e relevantes para a tomada de decisão e definição de metas.

Com base nas informações e conclusões apresentadas, recomenda-se ao gestor ter amplo conhecimento dos seus processos produtivos e ampliar suas habilidades com enfoque em estratégias e técnicas de gestão para definir qual método melhor atenderá as necessidades operacionais de sua empresa, e que lhe forneça os dados mais precisos para amparar as tomadas de decisões objetivando os melhores resultados.

Para maior discernimento do referido tema, recomenda-se aos usuários e gestores que aprofundem os estudos, sobre a análise de custos e explorem outros métodos de custeios para obtenção de um conhecimento de maior amplitude e embasamento aprimorado que muito contribuirá para entendimento geral do enfoque proposto.

\section{REFERÊNCIAS}

ABBAS, Katia; GONÇALVES, Marguit Neumann; LEONICE, Maury. Os métodos de custeio: vantagens, desvantagens e sua aplicabilidade nos diversos tipos de organizações apresentadas pela literatura. ConTexto, Porto Alegre, v.12, n.22, p.145-159, $2^{\circ}$ semestre 2012. Disponível em: <https://anaiscbc.emnuvens.com.br/anais/article/view/2560/2560> Acesso em: 05 out 2019.

BORGET, Altair; SCHULTZ, Charles Albino; SILVIA, Márcia Zanievicz. É o custeio por absorção o único método aceito pela contabilidade? 2008. Disponível em: 
$<$ https://anaiscbc.emnuvens.com.br/anais/article/viewFile/1370/1370> Acesso em: 08 jun. 2019.

CLEMENTE; Ademir; SOUZA, Alceu. Considerações de custos e valor da informação. Florianopolis - SC, Biblioteca Eletrônica, 2004. Disponível em: <http://www.encontrosbibli.ufsc.br/bibesp/esp_02/4_clemente.pdf > apud MELO, Janaina Ferreira Marques de; SEVERIANO FILHO, Cosmo. Desmistificando as limitações do uso do custeio por absorção. Contabilidade Vista \& Revista, v. 17, n. 3, p. 11-24, 11 maio 2009. Disponível em: <https:// revistas.face.ufmg.br/index.php/contabilidadevistaerevista/article/view/303>. Acesso em: 27 ago. 2019.

HORNBURG, Ricardo; WEISE, Andreas Dittmar; ZAGO, Camila Avozani. A importância do estudo de viabilidade econômica de projetos nas organizações comtemporâneas. Reserchgate, 2009. Disponível em: <https://www.researchgate.net/profile/Camila_Zago3/pub lication/238742986_A_IMPORTANCIA_DO_ESTUDO_DE_VIABILIDADE_ECONOMIC A DE PROJETOS NAS ORGANIZACOES COMTEMPORANEAS/links/5544d42f0cf24 07d397abfa/A-IMPORTANCIA-DO-ESTUDO-DE-VIABILIDADE-ECONOMICA-DE-PR OJETOS-NAS-ORGANIZACOES-COMTEMPORANEAS.pdf>. Acesso em: 11 set. 2019.

LIMA, Maurício. Custos logísticos: uma visão gerencial, 1998. Disponível em: $<$ https://www .ilos.com.br/web/custos-logisticos-uma-visao-gerencial/>. Acesso em: 05 nov. 2019.

MARTINS, Eliseu. Contabilidade de custos. 10 ed. São Paulo: Atlas, 2010. 369 p.

MARTINS, Eliseu. Contabilidade de custos. 9 ed. São Paulo: Atlas, 2003 apud SEVERIANO FILHO, Cosmo; MELO, Janaina Ferreira Marques de. Desmistificando as limitações do uso do custeio por absorção. Contabilidade Vista \& Revista, v. 17, n. 3, p. 1124, 11 maio 2009. Disponível em: <https://revistas.face.ufmg.br/index.php/contabilidadevista erevista/article/view/303>. Acesso em: 27 ago. 2019.

MELO, Janaina Ferreira Marques de; SEVERIANO FILHO, Cosmo. Desmistificando as limitações do uso do custeio por absorção. Contabilidade Vista \& Revista, v. 17, n. 3, p. 1124, 11 maio 2009. Disponível em: <https://revistas.face.ufmg.br/index.php/contabilidade vistaerevista/article/view/303>. Acesso em: 27 ago. 2019.

TEIXEIRA, Ivandi Silva. O Custeio variável: mecanismos para a Gestão da Produtividade. In: ENCONTRO NORDESTINO DE CONTABILIDADE; 1993, Olinda - PE. p.141-50 apud SEVERIANO FILHO, Cosmo; MELO, Janaina Ferreira Marques de. Desmistificando as limitações do uso do custeio por absorção. Contabilidade Vista \& Revista, v. 17, n. 3, p. 1124, 11 maio 2009. Disponível em: <https://revistas.face.ufmg.br/index.php/contabilidade vistaerevista/article/view/303>. Acesso em: 27 ago. 2019.

ZANLUCA, Jonatan de Sousa. Custo ou despesa? [2015]. Disponível em: $<$ http://www. portaldecontabilidade.com.br/tematicas/custo-fixo-variavel.htm>. Acesso em: 08 jun. 2019. 